\title{
Unsuspected cardiopulmonary abnormalities complicating bronchopulmonary dysplasia
}

\author{
S H ABMAN, F J ACCURSO, AND C M BOWMAN \\ Department of Paediatrics and Webb-Waring Lung Institute, University of Colorado School of \\ Medicine, USA
}

SUMmARY Bronchopulmonary dysplasia is a serious chronic lung disease of infancy but despite numerous problems such as poor growth, recurrent lower respiratory tract infections, and cor pulmonale, steady improvement and recovery may generally be expected. We report four infants with bronchopulmonary dysplasia in whom the cardiopulmonary course did not show the usual steady improvement. Each infant was found to have an unsuspected cardiopulmonary lesion in addition to lung disease: two had congenital heart disease and two upper airway obstruction. Three improved after surgical intervention but one patient died immediately after this. Persistent right ventricular hypertrophy in patients with bronchopulmonary dysplasia maintained on supplemental oxygen, and a particularly slow rate of recovery from the need for supplemental oxygen are markers that should lead to evaluation for coexisting cardiopulmonary abnormalities.

Bronchopulmonary dysplasia is a chronic lung disease of infancy characterised by persistent respiratory distress and oxygen dependency after oxygen and ventilator management in the newborn period. ${ }^{1}$ Mortality from bronchopulmonary dysplasia has been reported to be 30 and $50 \%$ and most deaths occur during the initial hospital admission. ${ }^{2}{ }^{3} \mathrm{De}-$ spite numerous problems such as poor growth, recurrent respiratory infections, pulmonary hypertension, and cor pulmonale, steady improvement and recovery may generally be expected with the provision of appropriate care. ${ }^{4}$

The speed of recovery after the initial lung insult has been attributed to a balance between the severity of the underlying lung disease and the rate of lung growth and healing. ${ }^{2}$ Although lung function in patients with bronchopulmonary dysplasia generally improves, the rate of improvement may vary widely. ${ }^{56}$ Parameters commonly used to assess overall status include growth and development, degree of respiratory distress, oxygen requirement, frequency of hospital admissions, and severity of cardiac disease-particularly right ventricular hypertrophy. Unfortunately, a variety of cardiac or pulmonary abnormalities could, if present, worsen a patient's status further and decrease the chance of complete recovery. These 'hidden' lesions would be difficult to recognise because they produce symptoms similar to the underlying disease, and would probably delay the patient's recovery. Furthermore, such lesions might contribute to the pathophysiology of bronchopulmonary dysplasia by worsening hypoxaemia or increasing pulmonary blood flow and pressure. Because of the importance of diagnosing any complicating coexisting lesions we have begun to investigate more completely and invasively the cardiopulmonary status of patients with bronchopulmonary dysplasia whose clinical status worsens or improves very slowly.

We report four infants with bronchopulmonary dysplasia whose cardiorespiratory problems and growth improved initially, but then plateaued or worsened. These four were found to have severe unsuspected cardiopulmonary lesions in addition to the lung disease. Each newly diagnosed problem was at least potentially treatable. We speculate that early diagnosis of coexisting problems will hasten the patient's recovery.

\section{Case reports}

Case 1. A girl of 32 weeks' gestation and birthweight $1630 \mathrm{~g}$ was intubated on day 1 for respiratory distress due to hyaline membrane disease. Her 
respiratory status improved over the first 72 hours but then worsened because of a patent ductus arteriosus. Her symptoms resolved with diuretics and fluid restriction. She was extubated, and on day 12 was transferred to a community hospital. Her chest radiograph showed small cystic lesions compatible with the early stages of bronchopulmonary dysplasia, her electrocardiogram showed right ventricular hypertrophy and a raised right systolic time interval $(0.43)$ but no anatomic abnormalities were found on echocardiogram. After two months she was discharged home, requiring about three litres oxygen per minute by nasal cannula to maintain a $\mathrm{PO}_{2}$ of $7.3 \mathrm{kPa}(55 \mathrm{~mm} \mathrm{Hg})$. Over the next seven months she grew poorly, had a minimal reduction in oxygen requirements, and suffered recurrent episodes of respiratory distress. At 10 months of age she was admitted to hospital for cardiac catheterisation because of clinical and electrocardiographic evidence of persistent pulmonary hypertension. Physical examination showed a small thin child whose length and weight were less than the fifth centile for corrected age and who had mild respiratory distress, a respiratory rate of 60 , and scattered rales bilaterally. She had tachycardia and a grade I/VI systolic murmur without gallop. The second heart sound was noticeably increased-most prominently in the pulmonary area. She did not have an active precordium or bounding pulses. There was no hepatomegaly or peripheral oedema. An electrocardiograph showed right ventricular hypertrophy but no evidence of left atrial enlargement. A right systolic time interval of 0.40 was found on echocardiogram. $\mathrm{Her} \mathrm{Po}_{2}$ was $4.4 \mathrm{kPa}(33 \mathrm{~mm} \mathrm{Hg})$ when she breathed room air and $7.9 \mathrm{kPa}(60 \mathrm{~mm} \mathrm{Hg})$ on two litres of oxygen per minute by nasal cannula. Cardiac catheterisation showed an atrial septal defect, patent ductus arteriosus, and pulmonary hypertension, with a mean pulmonary artery pressure of $27 \mathrm{~mm} \mathrm{Hg}$ on four litres of oxygen delivered by face mask. Left to right shunting through the ductus and atrial septal defect was noted. After closure of her patent ductus arteriosus and atrial septal defect she has shown steady but slow improvement in her room oxygenation, improved growth, and resolution of the echocardiographic and electrocardiographic evidence of right ventricular hypertrophy. She no longer needs supplemental oxygen, but has continued to require diuretic treatment for three years.

Case 2. A girl born at 34 weeks' gestation and weighing $2400 \mathrm{~g}$ developed severe respiratory distress after delivery and required positive pressure ventilation. After a long and complicated course she was discharged from hospital without home oxygen, but required digoxin for treatment of right heart failure due to presumed cor pulmonale secondary to bronchopulmonary dysplasia. She was lost to follow up until 18 months of age when she was brought to the local clinic for treatment of otitis media, conjunctivitis, and facial cellulitis. At that time her weight was well below the fifth centile, she had a noticeably increased second heart sound without murmur or gallop, her electrocardiograph showed right ventricular hypertrophy, and chest radiograph showed a large heart with diffuse bilateral infiltrates. She was admitted for treatment of her facial cellulitis with parenteral antibiotics and was later transferred to our hospital for evaluation and treatment of her severe hypoxaemia and congestive heart failure. On arrival, her transcutaneous $\mathrm{Po}_{2}$ in room air was $3.9 \mathrm{kPa}(29 \mathrm{~mm} \mathrm{Hg})$. Her echocardiogram showed a large patent ductus arteriosus, prolonged right systolic time interval $(0 \cdot 40)$, and left ventricular dysfunction. Cardiac catheterisation showed left to right shunting through an atrial septal defect, bidirectional shunting through a ventricular septal defect, and right to left shunting through a patent ductus arterious. In addition, she had an interrupted aortic arch between the left carotid and subclavian arteries and severe pulmonary hypertension with a pulmonary artery pressure of $90 \mathrm{~mm} \mathrm{Hg}$. She underwent cardiac surgery for ligation of the patent ductus arteriosus and correction of the interrupted arch. A lung biopsy taken during the surgery showed moderate hypertrophy of the arteriolar media and noticeable intimal proliferation, with early fibrosis within the proliferating intima consistent with grade III Heath-Edwards changes. Occlusion of medium sized arteries and mild alveolar septal fibrosis were noted. On the second day after operation, and despite mechanical ventilation, she died from a cardiac arrest secondary to severe hypoxia.

Case 3. A boy of 27 weeks' gestation and birthweight $1015 \mathrm{~g}$ required intubation in the delivery room for severe respiratory distress. His initial course and chest radiographs were consistent with hyaline membrane disease. He subsequently developed bronchopulmonary dysplasia and was not extubated until 48 days of age. His course was further complicated by staphylococcal bacteraemia and a candida urinary tract infection. He was discharged at 3 months of age on half a litre of oxygen per minute by nasal cannula to maintain a $\mathrm{PO}_{2}$ greater than $7.3 \mathrm{kPa}(55 \mathrm{~mm} \mathrm{Hg})$ at all times.

He subsequently required multiple admissions to hospital for lower respiratory tract infections and congestive heart failure. Because of poor growth and persistent electrocardiographic findings of right 
ventricular hypertrophy, he was admitted at $1 \frac{1}{2}$ years of age for cardiac catheterisation to rule out anatomic heart disease. Physical examination showed length and weight below the fifth centile for corrected age, a grade II/VI systolic murmur at the left sternal border, and a loud second heart sound. Findings at catheterisation were severe pulmonary hypertension with a pulmonary artery pressure of 88 $\mathrm{mm} \mathrm{Hg}$ when breathing room air $\left(\mathrm{PaO}_{2} 4.7 \mathrm{kPa}(35\right.$ $\mathrm{mm} \mathrm{Hg})$ ) and no anatomic defects. Home oxygen treatment was continued. He was readmitted at $2 \frac{1}{2}$ years of age to evaluate possible upper airway obstruction because of recurrent otitis media and intermittent nocturnal coughing and snoring. Physical examination showed mouth breathing and bilateral intraorbital oedema with bluish discolouration, his nasal mucosa seemed 'boggy' with watery rhinorrhea, and tonsillar hypertrophy was found. Breath sounds were clear. The second heart sound was still increased. His room air $\mathrm{TcPo}_{2}$ fell from 5.6 $\mathrm{kPa}(42 \mathrm{~mm} \mathrm{Hg})$ while awake to $3.9 \mathrm{kPa}(30 \mathrm{~mm} \mathrm{Hg})$ while sleeping during episodes of snoring. Tonsillectomy and adenoidectomy led to resolution of the snoring and recurrent otitis media. Cardiac catheterisation at age 4 years showed noticeable improvement in his pulmonary hypertension, with room air pulmonary artery pressure of $33 \mathrm{~mm} \mathrm{Hg}$. In addition, $\mathrm{TcPO}_{2}$ monitoring during sleep showed resolution of his sleep hypoxaemia. He is doing well and no longer requires supplemental oxygen at 5 years of age.

Case 4. A boy born at 26 weeks' gestation and weighing $680 \mathrm{~g}$ required intubation and positive pressure ventilation on day 2 of life because of severe respiratory distress from hyaline membrane disease. He developed radiographic and clinical evidence of bronchopulmonary dysplasia. His course was marked by frequent failures at extubation because of upper lobe atelectasis and numerous reintubations. He was finally extubated successfully at 103 days and was discharged at 4 months of age, requiring half a litre of oxygen per minute by nasal cannula to maintain $\mathrm{TcPo}_{2}$ greater than $7 \cdot 3 \mathrm{kPa}(55$ $\mathrm{mm} \mathrm{Hg}$ ) during sleep, feeds, and while awake. He required frequent admissions to hospital for reactive airways disease and viral pneumonias in spite of his home treatment of isoetharine, theophylline, and frusemide. He also showed poor growth, developmental delay, and cor pulmonale. Because of clinical and echocardiographic evidence of persistent right ventricular hypertrophy and frequent hospital admissions he underwent cardiac catheterisation at 10 months of age. At this time his pulmonary artery pressure was $30 \mathrm{~mm} \mathrm{Hg}$ when breathing room air $\left(\mathrm{PaO}_{2}, 5.6 \mathrm{kPa}(42 \mathrm{~mm} \mathrm{Hg})\right)$ and
$25 \mathrm{~mm} \mathrm{Hg}$ when breathing high oxygen concentration $\left(\mathrm{F}_{\mathrm{I}} \mathrm{O}_{2}\right.$ greater than $\left.0 \cdot 80\right)$. No anatomic defects were found. After discharge, he still required frequent admissions for treatment of reactive airways disease. At 19 months of age, because of his frequent hospital admissions, poor growth, and persistent echocardiographic evidence of right ventricular hypertrophy he underwent bronchoscopy. This showed a subglottic cyst that extended to the carina and caused $40 \%$ obstruction of the airway. Tracheostomy was performed. Since that time he has undergone further bronchoscopy for dilatation, and resection of the subglottic lesion. His oxygen requirement is slowly decreasing.

\section{Results}

The Table summarises the clinical course, findings, treatment, and outcome of the four infants reported. Each patient showed persistent evidence of increased pulmonary pressures and right ventricular hypertrophy. Furthermore, the three children followed in the outpatient clinic showed stable or worsening room air oxygenation (Figure). The failure to improve room air oxygenation over time in these patients is in considerable contrast to 22 other bronchopulmonary dysplasia patients on home oxygen treatment who have been followed during infancy and have been reported previously. ${ }^{3}$

\section{Discussion}

These four infants had unexpected but serious cardiopulmonary pathology unrelated to their bronchopulmonary dysplasia which contributed to their poor clinical status. All had poor growth, static oxygen requirements, and persistent right ventricular hypertrophy (Table). The coexisting lesions were diverse, and although cardiac catheterisation identified the problems in two, further evaluation, including bronchoscopy and monitoring of respiratory pattern and oxygenation during sleep, were necessary to uncover the pathology in the other two children.

This is the first report of a group of patients with bronchopulmonary dysplasia and severe existing cardiopulmonary defects. The three patients followed as outpatients represent five per cent of our outpatients with bronchopulmonary dysplasia who required home oxygen treatment between 1979 and 1981. It is important to note that in each case the infant's poor progress was originally attributed to the diagnosis of bronchopulmonary dysplasia, thus delaying recognition of the other cardiopulmonary abnormalities. Though difficult to detect, each 
Table Clinical summary of four patients with bronchopulmonary dysplasia and coexisting cardiopulmonary abnormalities

\begin{tabular}{|c|c|c|c|c|c|}
\hline $\begin{array}{l}\text { Case } \\
\text { No }\end{array}$ & Clinical course & $\begin{array}{l}\text { Age at diagnosis } \\
\text { of coexisting } \\
\text { lesion (years) }\end{array}$ & Findings & Treatment & Outcome \\
\hline 1 & $\begin{array}{l}\text { Poor growth } \\
\text { Persistent } \mathrm{RVH} \\
\text { Continual high } \mathrm{O}_{2} \text { requirement }\end{array}$ & 0.8 & ASD, PDA, PHT & Surgical correction & Improvement \\
\hline 2 & $\begin{array}{l}\text { Poor growth } \\
\text { Persistent RVH } \\
\text { Severe hypoxaemia }\end{array}$ & $3 \cdot 0$ & $\begin{array}{l}\text { ASD, VSD, PDA, } \\
\text { PHT, interrupted } \\
\text { aortic arch }\end{array}$ & Surgical correction & $\begin{array}{l}\text { Death on day } 2 \\
\text { after operation }\end{array}$ \\
\hline 3 & $\begin{array}{l}\text { Poor growth } \\
\text { Frequent hospital admissions } \\
\text { for CHF and respiratory distress } \\
\text { Persistent RVH } \\
\text { Nocturnal cough, snoring }\end{array}$ & 2.5 & $\begin{array}{l}\text { Nocturnal hypoxaemia } \\
\text { from obstructing } \\
\text { tonsils }\end{array}$ & $\begin{array}{l}\text { Tonsillectomy and } \\
\text { adenoidectomy }\end{array}$ & Improvement \\
\hline 4 & $\begin{array}{l}\text { Poor growth } \\
\text { Frequent hospital admissions } \\
\text { for RAD } \\
\text { Continual high } \mathrm{O}_{2} \text { requirement } \\
\text { Persistent } \mathrm{RVH}\end{array}$ & 1.6 & Subglottic cyst & $\begin{array}{l}\text { Resection } \\
\text { Tracheostomy }\end{array}$ & Improvement \\
\hline
\end{tabular}

$\mathbf{R V H}=$ right ventricular hypertrophy; $\mathrm{CHF}=$ congestive heart failure; $\mathrm{RAD}=$ reactive airways disease; $\mathrm{ASD}=$ atrial septal defect $; \mathrm{PDA}=$ patent ductus arteriosus; PHT=pulmonary hypertension; VSD=ventricular septal defect.

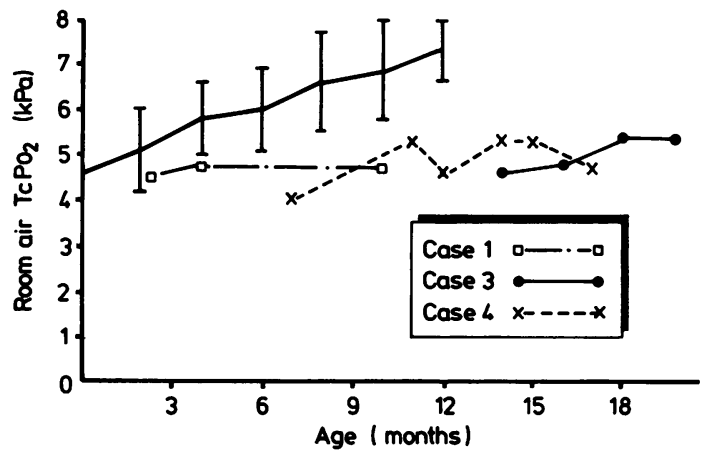

Figure Serial room air $\mathrm{TcPo}_{2}$ measurements in the three patients followed in the outpatient clinic. The solid line represents mean $\mathrm{TcPo}_{2}$ values of 22 other infants with bronchopulmonary dysplasia managed on home oxygen therapy. (Bars represent mean (SD)).

Conversion-SI to traditional units: $\mathrm{TcPo}_{2} 1 \mathrm{kPa} \approx 7.5 \mathrm{~mm} \mathrm{Hg}$.

coexisting abnormality was at least potentially reparable. We suggest that earlier diagnosis of these lesions would probably have resulted in fewer admissions to hospital, shortened duration of oxygen requirement, improved growth, and perhaps allowed survival of patient 2 .

Failure of infants with bronchopulmonary dysplasia to improve their resting $\mathrm{TcPo}_{2}$ should prompt evaluation of their cardiovascular and upper airway status. Patient 4, for example, showed little improvement in room air $\mathrm{TcPo}_{2}$ compared with other infants with bronchopulmonary dysplasia during infancy (Figure). Growth, oxygenation, and duration of ventilation while in the intensive care unit were not different in the infants with coexisting cardiopulmonary lesions when compared with other infants with bronchopulmonary dysplasia. Clinical differences became apparent only during the follow up period.

We have noted poor growth, static oxygen requirement, and persistence of right ventricular hypertrophy as important findings that prompted more extensive and invasive diagnostic evaluations of these patients. The time course of improvement in these parameters in patients with uncomplicated bronchopulmonary dysplasia is not described in detail. Previous studies have shown that these infants tend to have poor growth, persistent respiratory distress, and frequent hospital admissions (often due to respiratory infections) after discharge from the neonatal intensive care unit. ${ }^{4678}$ Clinical improvement, as measured by a reduction in hospital admissions, is often seen in the second year of life, and frequent hospital admissions thereafter may suggest a need for further evaluations. Unfortunately, frequency of admissions is a crude estimate of clinical status and may be influenced considerably by seasonal shifts in virulence of the respiratory viruses prevalent in the community. Since most infants with bronchopulmonary dysplasia steadily reduce their need for supplemental oxygen, ${ }^{56}$ however, a static oxygen requirement over several months, as shown by our three infants, may be a more sensitive and useful indicator of clinical status. 
Infants with bronchopulmonary dysplasia tend to require oxygen for variable but often long durations after hospital discharge, ranging from 9 to 75 weeks (mean 29.9 weeks) in one study. ${ }^{5}$ Serial measurements of $\mathrm{TcPo}_{2}$ while breathing room air may be more useful than the absolute duration of oxygen therapy in assessing the need for an additional cardiopulmonary evaluation. Although rates of improvement of room air $\mathrm{TcPO}_{2}$ are widely variable, infants with bronchopulmonary dysplasia generally show steady improvement, ${ }^{6}$ which three of our infants failed to show.

We have also found persistence of right ventricular hypertrophy to be a valuable indicator of potential coexisting abnormalities. Although previous studies $^{2910}$ have shown a high incidence of this in infants with bronchopulmonary dysplasia, only the study of Harrod et al followed serial electrocardiographic tracings after nursery discharge. ${ }^{11}$ In this study, seven of 12 patients with bronchopulmonary dysplasia had electrocardiographic evaluation both in the neonatal care unit and during follow up. Six patients initially showed right ventricular hypertrophy. At a mean follow up of 2.7 years (range 1 to 5 years), five showed persistent right ventricular hypertrophy and resolution had occurred in only one infant. In contrast, we have observed that most patients with bronchopulmonary hyperplasia do not have right ventricular hypertrophy at 1 year of age, even if they had it during the initial hospital admission, ${ }^{6}$ and hence we regard persistent right ventricular hypertrophy as an important sign of the need for further investigations. A likely explanation for this difference between the two studies is that our patients were treated with continuous home oxygen therapy whereas those in the study of Harrod et al were not and might, therefore, have been subject to episodic hypoxaemia.

The importance of this report is the finding of severe, unexpected, but treatable cardiopulmonary abnormalities in patients with bronchopulmonary dysplasia. Although logic suggests that a few children should have coexisting pathology, such defects may go unrecognised as physicians attribute persistent signs of respiratory distress, cor pulmonale and slow improvement in oxygenation to the abnormal lung mechanics and hypoxia of the lung disorder. In addition, it may be difficult to interpret subtle changes in clinical or radiographic examination in these patients. We suggest that persistent right ventricular hypertrophy in bronchopulmonary dysplasia, even among those receiving continuous supplemental oxygen, may be a sign of persistent, though perhaps episodic, hypoxaemia. Specifically, the oxygen therapy may be inadequate to prevent intermittent hypoxaemia during activity or sleep. Whatever the cause, oxygen therapy may need adjustment. Furthermore, these children may need more extensive evaluation to rule out additional cardiopulmonary problems. Studies such as bronchoscopy, echocardiography, cardiac catheterisation, and respiratory monitoring for hypoxaemia and sleep apnoea may be important steps in the diagnostic evaluation. We suggest that the longer a serious coexisting cardiopulmonary lesion remains undiagnosed and uncorrected the more severe will be the patient's course.

This work was supported in part by grants from the Cystic Fibrosis Foundation, National Institutes of Health (HD 00781), and American and Colorado Heart Associations. SHA is a fellow of the Cystic Fibrosis Foundation. CMB is a Clinician Scientist Awardee of the American Heart Association. The authors appreciate the assistance of Rose Marie Vukovich in the preparation of this manuscript.

\section{References}

${ }^{1}$ Northway WH, Rosen RC, Porter DY. Pulmonary disease following respiratory therapy of hyaline membrane disease. $N$ Engl $J$ Med 1967;276:357-68.

2 Johnson JD, Malachowski NC, Grobstein R, et al. Prognosis of children surviving with the aid of mechanical ventilation in the newborn period. J Pediatr 1974;84:272-6.

${ }^{3}$ Edwards DK, Dyer W, Northway WH. Twelve years experience with bronchopulmonary dysplasia. Pediatrics 1977;59:839-46.

${ }^{4}$ Markestad T, Fitzhardinge PM. Growth and development in children recovering from bronchopulmonary dysplasia. J Pediatr 1981;98:597-602.

5 Campbell AN, Zarfin Y, Groenveld M, Bryan MH. Low flow oxygen therapy in infants. Arch Dis Child 1983;58:795-8.

6 Abman SH, Accurso FJ, Koops BL. Experience in the outpatient management of infants with bronchopulmonary dysplasia on home oxygen. Clin Pediatr 1984; (in press).

${ }^{7}$ Mayes L, Perkett E, Stahlman M. Severe bronchopulmonary dysplasia: a retrospective review. Acta Paediatr Scand 1983;72: 225-9.

8 Yu VYH, Orgia AA, Lim SB, et al. Growth and development of very low birthweight infants recovering from bronchopulmonary dysplasia. Arch Dis Child 1983;58:791-4.

9 Fouron JC, Leguennec JC, Villemont D, et al. Value of echocardiography in assessing outcome of bronchopulmonary dysplasia of the newborn. Pediatrics 1980;65:529-35.

10 Halliday HL, Dumpit FM, Brady JP. Effects of inspired oxygen on echocardiographic assessment of pulmonary vascular resistance and myocardial contractility in BPD. Pediatrics $1980 ; 65: 536-40$.

1 Harrod JR, L'Heureux P, Wangensteen DD, Hunt CE. Longterm follow-up of severe respiratory distress syndrome treated with IPPB. J Pediatr 1974;84:277-86.

Correspondence to Dr S H Abman, 4200 East Ninth Avenue, Box C 220, Denver, Colorado 80262, USA.

Received 4 July 1984 